\title{
Fibra Bruta e Óleo em Dietas Práticas para Alevinos de Tilápia do Nilo (Oreochromis niloticus $)^{1}$
}

\section{Eduardo Arruda Teixeira Lanna², Luiz Edivaldo Pezzato ${ }^{3}$, Wilson Massamitu Furuya ${ }^{4}$, Carlos Alberto Vicentini ${ }^{5}$, Paulo Roberto Cecon $^{6}$, Margarida Maria Barros ${ }^{7}$}

RESUMO - Objetivou-se, neste estudo, avaliar os efeitos de diferentes níveis de fibra bruta e de óleo de soja em rações para a tilápia do Nilo. Utilizaram-se 24 aquários circulares de 250 L, dotados de sistema individual de reabastecimento de água e aquecimento.

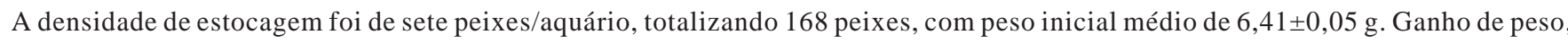
conversão alimentar aparente, taxa de crescimento específico e taxa de eficiência protéica foram avaliados. Foram analisados a composição química e o rendimento de carcaça, gordura visceral e índice hepatossomático dos peixes. O experimento foi realizado segundo um esquema fatorial 3 x 2 (três níveis de fibra bruta 6,00; 9,00 e 12,00\%, com e sem óleo de soja) no delineamento inteiramente ao acaso com quatro repetições. Verificou-se que a fibra interfere de forma significativa na digestibilidade aparente da dieta, com ação positiva para a proteína e negativa para a matéria seca, não interferindo na digestibilidade do extrato etéreo; que a fibra bruta não tem efeito significativo sobre o rendimento de carcaça e no depósito de gordura visceral, mas a inclusão de óleo à ração tem efeito significativo no depósito de gordura visceral; que a fibra resulta em efeito significativo na composição química da carcaça (teor de água e proteína), não tendo efeito sobre sua composição em gordura; e que a inclusão de gordura à ração diminui e eleva de forma significativa, respectivamente, o conteúdo de proteína e extrato etéreo da carcaça. Concluiu-se que, na fase de alevinagem $(6,40$ a 31,00g), podese utilizar na dieta da tilápia do Nilo até $9,00 \%$ de fibra bruta, e que a suplementação de níveis excessivos de lipídeos na dieta piora a composição da carcaça e resulta em maior depósito de gordura visceral.

Palavras-chave: digestibilidade, fibra bruta, linhagem tailandesa, nutrição, óleo

\section{Crude Fiber and Oil in Diets for Nile Tilapia (Oreochromis niloticus)}

\begin{abstract}
The objective of this research was to evaluate the effects of different crude fiber and soybean oil levels in diets for Tilapia Nile. Twenty-four circular fishbowls of 250 liters, with an individual system of water replenishment and heating, were used. The stocking rate was of seven fishes/fishbowl, totalizing 168 fishes, with average initial weight of $6.41 \pm 0.05 \mathrm{~g}$. Weight gain, apparent feed:gain ratio, specific growing rate and protein efficiency rate were evaluated. The chemical composition and carcass yield, eviscerated carcass and hepatossomatic index were also studied. A completely randomized design was used, in a 3 x 2 factorial scheme, being three crude fiber levels $(6.00,9.00 \%$, and $12.00 \%)$, and two soybean oil levels $(0.0$ and $10.0 \%)$, with four replicates. It was verified that it is possible to use, in the diet, levels up to $12.00 \%$ of crude fiber and its excess tends to decrease the weight gain and the protein efficiency rate, besides worsening the feed:gain ratio; the fiber significantly affect the dietary apparent digestibility, with positive and negative effect on the protein and dry matter digestibility, respectively, and without effect on the ether extract digestibility; the crude fiber did not significantly affect the carcass yield and the eviscerated fat deposition. However, the oil addition to the diet showed significant effect on the eviscerated fat deposition; the fiber resulted in significant effect on the carcass chemical composition of the carcass (water and protein contents), without effect on the fat composition; and the fat addition to the diet significantly decreased and increased, respectively, the carcass protein and ether extract contents. It was concluded that, in the growing phase (from 6.40 to $31.00 \mathrm{~g}$ ), the dietary crude fiber levels up to $9.00 \%$ can be fed for Nile tilapia and the supplementation of high dietary lipid levels decrease the carcass composition and result in higher eviscerated fat deposition.
\end{abstract}

Key Words: crude fiber, digestibility, fish nutrition, tailandesa lineage, oil

\footnotetext{
${ }^{1}$ Parte da tese de Doutorado do primeiro autor apresentada à UNESP-Botucatu, SP

2 Prof. Dr., Depto. de Zootecnia/UFV, MG, Brasil (elanna@ufv.br).

3 Prof. Dr., Depto. Melh. e Nutr. Animal - UNESP - Botucatu, SP (epezzato@fca.unesp.br).

${ }^{4}$ Prof. Dr., Depto. de Zootecnia/UEM, PR, Brasil (furuya@wnet.com.br).

5 Prof. Dr., Depto. de Ciências Biológicas/UNESP, SP, Brasil.

6 prof. Dr., Depto. de Informática/UFV, MG, Brasil (cecon@dpi.ufv.br).

7 Zootecnista do Dep. Melh. e Nutr. Animal - UNESP - Botucatu, SP, Brasil.
} 


\section{Introdução}

O balanceamento de nutrientes obtido pelos peixes em seus ambientes naturais não ocorre quando os mesmos se encontram em ambientes confinados, quer pela ausência ou pela limitação de alimentos (Pezzato, 1990). Em função disto, em cultivo intensivo, os peixes dependem da utilização de rações comerciais que satisfaçam as necessidades de nutrientes essenciais e de energia para garantir para o desenvolvimento e a rentabilidade (Cantelmo, 1989). Contudo, as rações balanceadas utilizadas nos sistemas intensivos têm custo relativamente alto, pois são usados produtos e subprodutos de origem animal.

No intuito de reduzir o custo das rações utilizadas em cultivos de peixes, parte dos ingredientes de origem animal é substituída por ingredientes de origem vegetal, resguardando-se o balanço de nutrientes essenciais, tanto pela suplementação com aminoácidos sintéticos quanto por complexos vitamínicos-mineral, não sendo, entretanto, consideradas as possíveis adaptações fisiológicas no organismo destes animais, em função da alteração dos níveis de fibra bruta da dieta (Cantelmo, 1989; Pezzato, 1990).

Vários estudos têm demonstrado que a variação dos níveis de fibra bruta em dietas para peixes pode alterar o desempenho produtivo, a digestibilidade, a velocidade de trânsito gastrintestinal, a morfologia do trato digestivo e o rendimento e a composição química da carcaça dos peixes, principalmente no seu teor de lipídios (Buhler \& Halver, 1961; Leary \& Lovell, 1975; Dupree \& Sneed, 1966; Shiau et al., 1988).

Embora o NRC (1993) recomende que rações compostas por ingredientes de origem vegetal devem conter de 3,0 a 5,0\% de fibra bruta, há pesquisas demonstrando que muitas espécies de peixes podem tolerar níveis de até $8,0 \%$ nas rações, sendo que concentrações superiores podem deprimir o crescimento dos animais (Leary \& Lovell, 1975; Dupree \& Sneed, 1966; Dioundick \& Stom, 1990). Há, portanto, a necessidade de se conhecer os níveis máximos toleráveis de fibra bruta que devem conter as rações das diferentes espécies de peixes.

A composição corporal dos peixes também pode ser alterada pela utilização de teores elevados de lipídios nas dietas, influindo nas características da carcaça, com reflexos em sua conservação e conseqüente comercialização (Hanley, 1991; Van der Meer et al., 1997). Conduziu-se este experimento com o objetivo de avaliar os efeitos de diferentes níveis de fibra bruta e de óleo no desempenho produtivo, digestibilidade aparente, na composição química da carcaça e nas alterações anatomopatológicas, em tilápia do Nilo.

\section{Material e Métodos}

Este estudo foi conduzido no Laboratório de Nutrição de Organismos Aquáticos da FMVZ Campus de Botucatu, unidade integrada ao Centro de Aqüicultura da UNESP, no período de 12/08 a 10/11/1998.

Cento e sessenta e oito tilápias (Oreochromis niloticus) revertidas sexualmente, com 45 dias de idade, peso inicial médio de $6,41 \pm 0,05 \mathrm{~g}$ e comprimento total médio de $5,57 \pm 0,16 \mathrm{~cm}$ foram distribuídas em delineamento inteiramente ao acaso, segundo um esquema fatorial 3 (níveis de fibra) x 2 (com e sem óleo), com quatro repetições e seis peixes por unidade experimental.

Foram confeccionadas seis rações isoprotéicas segundo as normas apresentadas pelo NRC (1993), contendo três níveis de fibra bruta $(6,00 ; 9,00 \mathrm{e}$ $12,00 \%)$, com ou sem óleo, caracterizando os tratamentos T6-0 (6,00\% de FB e 0,00\% de óleo), T6-10 (6,00\% de FB e $10,00 \%$ de óleo), T9-0 (9,00\% de FB e $0,00 \%$ de óleo), T9-10 (9,00\% de FB e $10,00 \%$ de óleo), T12-0 (12,00\% de FB e 0,00\% de óleo) e T12-10 (12,00\% de FB e 10,00\% de óleo) (Tabela 1). As rações foram peletizadas com dois diâmetros $(1,50 \mathrm{~mm}$ e 3,36 mm) destinados, respectivamente, às fases inicial e final do experimento.

Foram utilizados 24 aquários circulares $(250 \mathrm{~L}$ cada) dotados de sistema individual de reabastecimento de água, através de biofiltro, e aquecimento controlado por termostato e aeração.

A temperatura da água dos aquários foi aferida às $8 \mathrm{~h}$ e $16 \mathrm{~h}$, o controle do $\mathrm{pH}$, da amônia e do teor de oxigênio dissolvido na água a cada sete dias, respectivamente.

Os peixes foram alimentados à vontade, duas vezes ao dia, imediatamente após a leitura da temperatura da água dos aquários, em uma quantidade que possibilitou ingestão máxima, sem que houvesse perdas de ração. Diariamente, realizou-se a limpeza dos aquários, por sifonagem, para retirada de sobras de ração e fezes, com reposição de $20,00 \%$ da água dos mesmos.

Os peixes foram pesados no início do período experimental, aos 30, 60 e 76 dias, utilizando-se uma 
balança com precisão de centésimos, sendo as pesagens antecipadas por 24 horas de jejum. O comprimento total dos peixes foi medido apenas no início e final do estudo.

Ganho de peso (GP), conversão alimentar aparente (CAA), taxa de crescimento específico (TCE) e taxa de eficiência protéica (TEP). Estudaram-se ainda as seguintes características de carcaça: composição química, rendimento de carcaça (RC), gordura visceral $(\mathrm{GV})$ e índice hepatossomático (IHS) foram avaliados.

As análises macro e microscópica do sistema digestório dos peixes foram realizadas após a pesagem final (77 dias), quando foram retirados quatro peixes de cada tratamento. Para proceder ao exame detalhado dos órgãos, foram realizadas três incisões, uma paralela ao dorso na região abdominal ventral e duas no sentido dorso-ventral, uma próxima ao opérculo e outra na abertura do poro urogenital. Assim, as vísceras ficaram expostas permitindo análise completa com o emprego de lupa com aumento 10X e assumindo como critério de padrão avaliativo a coloração e a morfologia dos órgãos dos indivíduos do tratamento T6-0 (controle).
Para preparação do material para a análise microscópica, recolheu-se parte do intestino médio, que foi imediatamente fixada em solução de Bouim, para posterior preparação das lâminas, seguindo a rotina histológica mediante coloração hematoxilina-eosina e a técnica histológica doácido periódico de SCHIFF(PAS). Essas lâminas foram empregadas para mensuração do comprimento das pregas do epitélio intestinal, utilizando-se o equipamento mini-mopi; os resultados foram submetidos à análise de regressão polinomial.

A avaliação do coeficiente de digestibilidade aparente foi realizada após o período de desempenho produtivo e da coleta de peixes para análise do sistema digestório. Foram utilizados seis aquários circulares $(250 \mathrm{~L})$, para alimentação dos peixes, e seis aquários de ensaios de digestibilidade $(100 \mathrm{~L})$, para coleta das fezes.

Os peixes receberam as mesmas rações (Tabela 1) acrescidas de $0,1 \%$ de óxido de crômio-III $\left(\mathrm{Cr}_{2} \mathrm{O}_{3}\right)$. Para tanto, empregaram-se as mesmas tilápias dos respectivos tratamentos, unindo-se as remanescente das repetições em um único aquário, em gaiolas de náilon, mantendo-se o mesmo regime alimentar. As fezes foram coletadas no período da manhã, em aquários de digestibilidade, em intervalos de quatro

Tabela 1 - Composição percentual das rações experimentais

Table 1 - Percentage composition of the experimental diets

\begin{tabular}{|c|c|c|c|c|c|c|}
\hline \multirow[t]{2}{*}{$\begin{array}{l}\text { Ingrediente }(\%) \\
\text { Ingredient }(\%)\end{array}$} & \multicolumn{6}{|c|}{$\begin{array}{c}\text { Tratamento } \\
\text { Treatment }\end{array}$} \\
\hline & T6-0 & T6-10 & T9-0 & T9-10 & $\mathrm{T} 12-0$ & $\mathrm{~T} 12-10$ \\
\hline Fubá de milho (Corn meal) & 39,38 & 27,39 & 31,83 & 20,05 & 24,50 & 12,50 \\
\hline Farelo de soja (Soybean meal) & 52,00 & 53,80 & 53,00 & 54,60 & 53,80 & 55,60 \\
\hline Bagaço de cana (Cane bagasse) & 5,28 & 5,47 & 11,82 & 12,00 & 18,35 & 18,55 \\
\hline DL-Metionina (DL-methionine) & 0,02 & 0,02 & 0,03 & 0,03 & 0,03 & 0,03 \\
\hline Óleo de soja (Soybean oil) & - & 10,00 & - & 10,00 & - & 10,00 \\
\hline Fosfato bicálcico (Dicalcium phosphate) & 2,80 & 2,80 & 2,80 & 2,80 & 2,80 & 2,80 \\
\hline BHT (antioxidante) (Antioxidant) & 0,02 & 0,02 & 0,02 & 0,02 & 0,02 & 0,02 \\
\hline Supl. Vitam. Mineral (1) (Vit. min. supplement) & 0,50 & 0,50 & 0,50 & 0,50 & 0,50 & 0,50 \\
\hline Total & 100 & 100 & 100 & 100 & 100 & 100 \\
\hline \multicolumn{7}{|l|}{ Valores calculados (Calculated values) } \\
\hline Proteína bruta, \% (Crude protein, \%) & 26,04 & 26,08 & 26,08 & 26,05 & 26,03 & 26,08 \\
\hline Extrato etéreo, \% (Ether extract, \%) & 1,18 & 11,01 & 1,11 & 10,94 & 1,04 & 10,84 \\
\hline Fibra bruta, \% (Crude fiber, \%) & 6,14 & 6,14 & 9,14 & 9,13 & 12,13 & 12,14 \\
\hline Energia digestível, $\mathrm{kcal} / \mathrm{kg}$ (Digestible energy, $\mathrm{kcal} / \mathrm{kg}$ ) & 3.029 & 3.539 & 2.813 & 3.324 & 2.598 & 3.108 \\
\hline Cálcio, \% (Calcium, \%) & 0,30 & 0,30 & 0,30 & 0,29 & 0,29 & 0,29 \\
\hline Fósforo disponível, \% (Available phophorus, \%) & 0,61 & 0,61 & 0,61 & 0,60 & 0,60 & 0,60 \\
\hline Relação ED:PB (DE:CP ratio) & 116,32 & 135,70 & 107,86 & 127,60 & 99,81 & 119,17 \\
\hline
\end{tabular}

\footnotetext{
${ }^{1}$ Suplemento vitamínico e mineral (Min. and vit. supplement) (Supremais) níveis de garantia/kg do produto: vit.A 600.000 UI; vit. $\mathrm{D}_{3}$ $100.000 \mathrm{UI}$; vit.E $6.000 \mathrm{mg}$; vit.K $\mathrm{K}_{3} 1.200 \mathrm{mg}$; vit. $\mathrm{B}_{1} 2.400 \mathrm{mg}$; vit. $\mathrm{B}_{2} 2.400 \mathrm{mg}$; vit. $\mathrm{B}_{6} 24000 \mathrm{mg}$; Vit. $\mathrm{B}_{12} 2.400 \mathrm{mg}$; ác. fólico (folic acid) $600 \mathrm{mg}$; ác. pantotênico (panthotenic acid) $6000 \mathrm{mg}$; vitC $24 \mathrm{~g}$; biotina (biotin) $24 \mathrm{mg}$; colina (cholin) $54 \mathrm{~g}$; niacina (niacin) $12.000 \mathrm{mg}$; Fe
} 5.000 mg; Cu 300 mg; Mn 2000 mg; Zn 3000 mg; I 10 mg; Co 1 mg e Se 10 mg.

\section{R. Bras. Zootec., v.33, n.6, p.2177-2185, 2004 (Supl. 3)}


dias, durante 12 dias, caracterizando três repetições. Diariamente, o material coletado era centrifugado a $6000 \mathrm{rpm} / \mathrm{min}$, desidratado em estufa a $55^{\circ} \mathrm{C}$ e conservado a $-20^{\circ} \mathrm{C}$ para posteriores análises bromatológicas.

Os coeficientes de digestibilidade aparente foram obtidos empregando-se o método indireto, com o marcador óxido de crômio-III $\left(\mathrm{Cr}_{2} \mathrm{O}_{3}\right)$, de acordo com a metodologia descrita por Austreng (1978). A determinação da concentração do óxido crômico foi realizada pelo método da absorção atômica (Willians et al., 1962), utilizando-se o aparelho GBC Avante E Atomic Absorpition Spectrometer, e o coeficiente de digestibilidade aparente calculado segundo Nose (1966):

$$
\mathrm{Da}_{(\mathrm{n})}=100-\left[100\left(\frac{\% \mathrm{Cr}_{2} \mathrm{O}_{3 \mathrm{r}}}{\% \mathrm{Cr}_{2} \mathrm{O}_{3 \mathrm{f}}}\right) \times\left(\frac{\% \mathrm{~N}_{\mathrm{f}}}{\% \mathrm{~N}_{\mathrm{r}}}\right)\right]
$$

em que $\mathrm{Da}_{(\mathrm{n})}=$ digestibilidade aparente do nutriente; $\mathrm{Cr}_{2} \mathrm{O}_{3 \mathrm{r}}=\%$ de óxido de crômio na ração; $\mathrm{Cr}_{2} \mathrm{O}_{3 \mathrm{f}}=$ $\%$ de óxido de crômio nas fezes; $\mathrm{N}_{\mathrm{r}}=\%$ Nutrientes na ração; $\mathrm{N}_{\mathrm{f}}=\%$ nutriente nas fezes.

As tilápias foram anestesiadas e sacrificadas no início e no final do experimento, para análises das carcaças. Essas foram utilizadas para se determinar o rendimento de carcaça, os níveis de gordura visceral, o índice hepatossomático e a composição química da carcaça.

Os dados foram interpretados por meio de análises de variância e de regressão. As médias dos fatores qualitativos foram comparadas pelo teste Tukey, adotando-se o nível de 5\% de probabilidade. Para os fatores quantitativos, os modelos foram escolhidos com base na significância dos coeficientes de regressão utilizando-se o teste F, a $5 \%$ de probabilidade, no coeficiente de determinação e no fenômeno em estudo.

\section{Resultados e Discussão}

O sistema individual de reabastecimento, através de biofiltro, possibilitou aeração uniforme e a renovação total da água dos aquários a cada 1 hora e 30 minutos. O sistema manteve também a temperatura da água sob controle. Os valores médios de temperatura $\left(25,80 \pm 0,27^{\circ} \mathrm{C}\right), \mathrm{pH}(7,17 \pm 0,08)$, oxigênio dissolvido $(5,32 \pm 0,27 \mathrm{mg} / \mathrm{L})$ e amônia total $(0,037 \pm$ 0,01 ppm), obtidos durante o período experimental, mantiveram-se dentro da faixa recomendada por Castagnolli \& Cyrino (1986), não influenciando o desempenho dos peixes.

Não houve interação entre os níveis de fibra bruta e óleo, assim como não foram observadas diferenças significativas $(\mathrm{P}>0,05)$ entre os resultados médios de ganho de peso (GP), conversão alimentar aparente (CAA), taxa de crescimento específico (TCE) e taxa de eficiência protéica (TEP) (Tabela 2).

Esses resultados assemelham-se aos obtidos por El Sayed (1991), que, em estudo realizado com híbridos de tilápias (Oreochromis niloticus x Tilápia zilli), utilizou rações contendo bagaço de cana cozido e não-cozido (30,0\% de proteína bruta, $4.600 \mathrm{kcal} / \mathrm{kg}$ de energia bruta e $22,0 \%$ de fibra bruta) e não encontrou diferenças significativas para crescimento, conversão alimentar, eficiência protéica e fator de condição. Resultados semelhantes também foram obtidos, para o crescimento em tilápia do Nilo, por Hanley (1991), e com juvenis de pacu, por Van der Meer et al. (1997).

Apesar da falta de diferença estatística, provavelmente em função dos elevados coeficientes de variação obtidos nos referidos parâmetros (Tabela 2), observa-se, com base no índice relativo de comparação (IRC\%), que, independentemente da suplementação ou não de óleo, a elevação dos teores de fibra proporcionou redução numérica tanto para o ganho de peso quanto para a taxa de crescimento específico, assemelhando-se, desta forma, aos resultados obtidos por Dioundick \& Stom (1990) e às recomendação do NRC (1993), de que a utilização de rações com elevadas concentrações de fibra bruta deprimem o crescimento de peixes.

Como as relações energia:proteína das rações experimentais não se apresentaram equivalentes (Tabela 1), os melhores valores numéricos médios para a conversão alimentar aparente (CAA) estão relacionados com o maior nível energético (dietas suplementadas com $10 \%$ de óleo), provavelmente em função do menor consumo, porém sem apresentar variação aparente com a elevação dos teores de fibra bruta da dieta. Similar efeito de níveis crescentes de fibra sobre aCAA, também foi observado por Dioundick \& Stom (1990) em estudo conduzido com tilápias.

Os peixes alimentados com dietas suplementadas com óleo apresentaram taxa de eficiência protéica (TEP) semelhantes, em torno de 4,03. Entretanto, para os peixes alimentados com as dietas sem suplementação de óleo, apesar de a TEP não ter variado entre os níveis de $6 \%$ e $9 \%$ de fibra bruta 


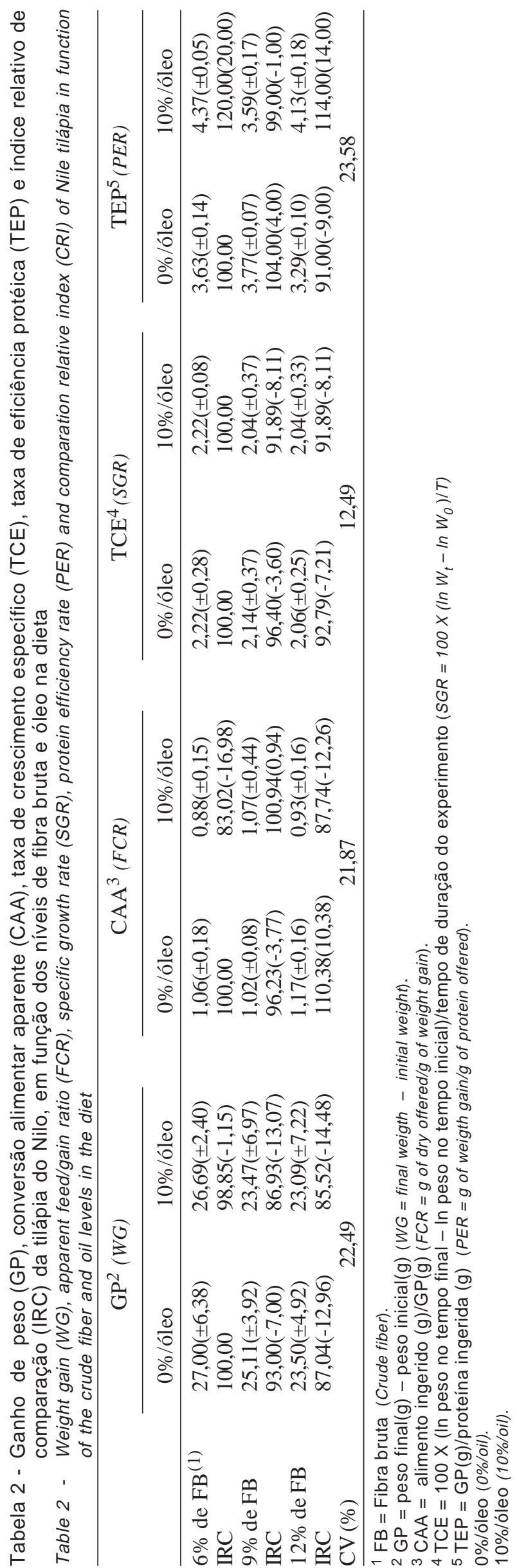

(em torno de 3,70 ), a utilização de dietas com 12\% de fibra bruta proporcionou redução da TEP para 3,29 , provavelmente resultado do menor nível energético desta dieta.

Todos os tratamentos apresentaram valores médios de TEP superiores aos obtidos por Dioundick \& Stom (1990) com a tilápia mossambica. Esses autores obtiveram valores médios de TEP variando de 1,53 a 0,88 . Foram também superiores ao observado por Oliveira (1994), quando os valores de TEP variaram de 1,59 a 1,67, em experimento com a tilápia do Nilo com peso inicial médio de 1,52 $\pm 0,04 \mathrm{~g}$, uma vez que foi utilizado menor teor de proteína neste experimento (Tabela 1).

Os valores médios dos coeficientes de digestibilidade aparente (CDA) da matéria seca (MS), proteína bruta $(\mathrm{PB})$ e extrato etéreo (EE), em função dos níveis de fibra bruta e de óleo das dietas, encontram-se nas Tabelas 3 e 4, respectivamente.

Não houve interação entre os níveis de fibra bruta e óleo e nem efeito da suplementação de óleo nos coeficientes de digestibilidade aparente avaliados neste estudo. Contudo, a elevação dos níveis de fibra bruta da dieta proporcionou redução linear $(\mathrm{P}<0,01)$ no CDA da MS ( $\left.\mathrm{Y}=81,0688-1,6629 \mathrm{FB}, \mathrm{r}^{2}=0,93\right) \mathrm{e}$ aumento linear $(\mathrm{P}<0,05)$ sobre o $\mathrm{CDA}$ da $\mathrm{PB}$ $\left(\mathrm{Y}=90,3283+0,3125 \mathrm{FB}, \mathrm{r}^{2}=0,54\right)$. Por outro lado, $\mathrm{o}$ aumento do nível de fibra bruta das rações não afetou o coeficiente de digestibilidade do $\mathrm{EE}(\mathrm{Y}=90,51)$.

Os resultados obtidos neste estudo diferem dos obtidos por Hilton et al. (1983), que, em pesquisa realizada com trutas com peso inicial médio de $5,30 \pm 0,20 \mathrm{~g}$, verificaram que níveis maiores de fibra bruta diminuíram a digestibilidade aparente de todos os nutrientes da ração.

Esses resultados são contrários, ainda, aos obtidos por Pereira-Filho (1989) em estudo com a carpa comum; Dioundick \& Stom (1990) com a tilápia e Garcia et al. (1999) em estudo realizado com a piracanjuba pesando $17,40 \pm 3,06$ g. Segundo esses autores, os maiores níveis de fibra bruta reduzem a digestibilidade da proteína bruta da ração.

Não houve efeito significativo da suplementação de óleo sobre a digestibilidade aparente das frações matéria seca e proteína bruta. Entretanto, a inclusão de $10,00 \%$ de óleo nas rações melhorou $(\mathrm{P}<0,01)$ o coeficiente de digestibilidade do EE (Tabela 4). Tal fato corrobora as observações de Hepher (1988), de que o teor de lipídio dietético pode influenciar o coeficiente de digestibilidade em peixes.

Os valores médios de rendimento de carcaça 
Tabela 3 - Valores médios para coeficiente de digestibilidade (\%) da matéria seca, proteína bruta, extrato etéreo, em função dos níveis de fibra bruta na dieta

Table 3 - Mean values for coefficients of digestibility (\%), of dry matter, crude protein and ether extract, in function of the crude fiber levels in the diet

\begin{tabular}{lcccc}
\hline $\begin{array}{l}\text { Fração } \\
\text { Fraction }\end{array}$ & $\begin{array}{c}\mathrm{CV} \\
(\%)\end{array}$ & $\begin{array}{c}\text { Fibra bruta } \\
\text { Crude fiber }\end{array}$ & \multicolumn{2}{c}{$\begin{array}{c}\text { Óleo de soja } \\
\text { Soybean oil }\end{array}$} \\
\cline { 4 - 5 } & & & $0 \%$ & $10 \%$ \\
\hline Matéria seca & 1,36 & $6 \%$ & 71,17 & 72,25 \\
Dry matter & & $9 \%$ & 64,30 & 65,21 \\
& & $12 \%$ & 62,37 & 61,56 \\
Proteína bruta & 0,90 & $6 \%$ & 90,56 & 92,72 \\
Crude protein & & $9 \%$ & 93,77 & 94,57 \\
& & $12 \%$ & 94,20 & 92,97 \\
Extrato etéreo & \multirow{2}{*}{3,63} & $6 \%$ & 85,81 & 97,84 \\
Ether extract & & $9 \%$ & 83,44 & 97,22 \\
& & $12 \%$ & 97,22 & 97,31 \\
\hline
\end{tabular}

Tabela 4 - Médias (\%) para coeficiente de digestibilidade de matéria seca (MS), proteína bruta (PB), extrato etéreo (EE), em função dos níveis de óleo na dieta

Table 4 - Means (\%) for coefficients of digestibility of dry matter (DM), crude protein (CP) and ether extract $(E E)$, in function of the oil levels in the diet

\begin{tabular}{lccc}
\hline & \multicolumn{3}{c}{ Variável } \\
Nariable \\
Nível de óleo & $\mathrm{MS}(\%)$ & $\mathrm{PB}(\%)$ & $\mathrm{EE}(\%)$ \\
\cline { 2 - 4 } Oil level & $D M$ & $C P$ & $E E$ \\
\hline $0 \%$ & $65,92 \mathrm{a}$ & $92,85 \mathrm{a}$ & $83,58 \mathrm{~b}$ \\
$10 \%$ & $66,28 \mathrm{a}$ & $93,43 \mathrm{a}$ & $97,45 \mathrm{a}$ \\
\hline
\end{tabular}

a,b Médias, na coluna, seguidas de letras diferentes, diferem $(P<0,01)$, pelo teste $F$.

$a, b$ Means, in column, followed by different letters, differ $(P<.01)$ by F test.

(RC), teor de gordura visceral (GV) e índice hepatossomático (IHS) dos peixes dos diferentes tratamentos encontram-se nas Tabelas 5 e 6 .

Não houve interação entre os níveis de fibra bruta e óleo e não foram observados efeitos significativos dos níveis de fibra bruta e óleo sobre o RC $(\mathrm{Y}=59,64)$ e dos níveis de fibra bruta sobre a $\mathrm{GV}(\mathrm{Y}=0,16)$.

Apesar da ausência de variação estatística, aplicando-se o IRC em função dos níveis de fibra bruta sobre os resultados de gordura visceral, verificou-se que para os peixes alimentados com as dietas sem suplementação de óleo, o teor de gordura visceral foi $25,00 \%$ superior para aqueles alimenta- dos com $6 \%$ de fibra bruta em relação aos demais níveis, que não apresentaram variação aparente. Contudo, a variação dos níveis de fibra nas dietas suplementadas com óleo não afetaram este parâmetro (Tabela 5).

Tendência de menores depósitos de lipídios nos peixes, em função do nível de fibra bruta da ração, corrobora os resultados obtidos por Anderson et al. (1984), Shiau et al. (1988) e Pereira-Filho et al. (1994).

Por outro lado, observou-se que a suplementação com $10 \%$ de óleo afetou $(\mathrm{P}<0,01)$ o teor de gordura visceral, que foi, em média $272,46 \%$ maior para rações com 10,00\% de óleo (Tabela 6), provavelmente em função da maior relação energia:proteína dessas dietas (Tabela 1). Estes resultados assemelham-se aos obtidos por Hanley (1991) e Van der Meer (1997), confirmando a capacidade das tilápias em estocarem quantidades significativas de lipídios, sobretudo nas vísceras.

Apesar de o índice hepatossomático (IHS) não ter sido afetado pela suplementação de óleo, observouse variação quadrática $(\mathrm{P}<0,05)$, em função da elevação dos níveis de fibra bruta, que aumentou até o nível estimado de $8,73 \%$ de fibra na ração $\left(\mathrm{Y}=-1,3572+0,6251 \mathrm{FB}-0,0358 \mathrm{FB}^{2}, \mathrm{r}^{2}=1,00\right)$, provavelmente em conseqüência da deposição lipídica no fígado. Acima deste valor, observou-se comportamento similar ao verificado por Anderson et al. (1984), Shiau et al. (1988), Pereira-Filho et al. (1994) e Garcia et al. (1999).

Os valores médios da MS, PB e EE da carcaça encontram-se nas Tabelas 5 e 6 . Não houve interação entre os níveis de fibra bruta e óleo sobre a composição corporal. Entretanto, a elevação dos teores de fibra reduziu de forma linear $(\mathrm{P}<0,05)$ o teor de MS ( $\left.\mathrm{Y}=89,3513-0,2329 \mathrm{FB}, \mathrm{r}^{2}=0,97\right)$ e aumentou linearmente $(\mathrm{P}<0,05)$ o teor de proteína bruta da carcaça $\left(\mathrm{Y}=75,9150+0,3937 \mathrm{FB}, \mathrm{r}^{2}=0,98\right)$, sem afetar o teor de EE da carcaça $(Y=8,65)$.

Esses resultados são conflitantes com a literatura consultada. Shiau et al. (1988) observaram que tilápias alimentadas com diferentes níveis de carboximetilcelulose (CMC) (2,0; 6,0; 10,0 e 14,0\%) não apresentaram diferenças na composição protéica da carcaça, porém observaram decréscimo nos valores do extrato etéreo com a elevação dos teores de CMC. Resultado semelhante foi obtido por Anderson et al. (1984) com essa mesma espécie. Pereira-Filho et al. (1994), trabalhando com o matrinxã, com peso médio de $125 \mathrm{~g}$, observaram elevação dos teores de proteína 
Tabela 5 - Valores médios para rendimento de carcaça (RC), gordura visceral (GV), índice hepatossomático (IHS), índice relativo de comparação (IRC) e composição química da carcaça

Table 5 - Mean values for carcass yield (CY), visceral fat (VF), hepatosomatic índex (HIS), comparation relative index (CRI) and chemical composition the carcass

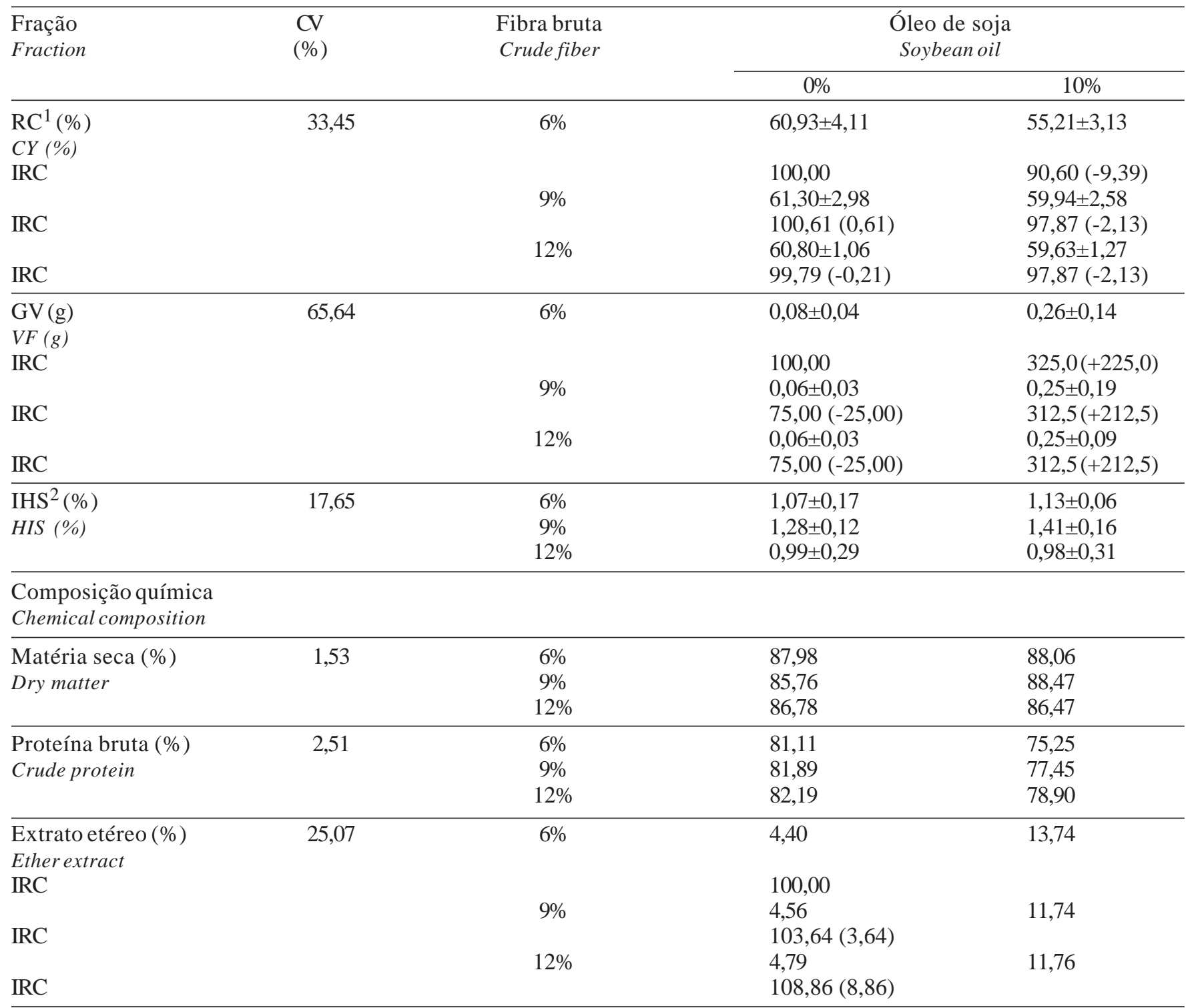

${ }^{1} \mathrm{RC}=$ [peso vivo total - peso dos rejeitos(cabeça, vísceras e nadadeiras)/peso vivo total] $\mathrm{X} 100$.

${ }^{2} \mathrm{IHS}=100 \times$ [peso do fígado $(\mathrm{g}) /$ peso vivo total $\left.(\mathrm{g})\right]$

$2 \mathrm{HSI}=100 \times$ [liver weigth, g/body weight, g].

e cinzas corporais e decréscimo de gordura para níveis crescentes de fibra bruta $(2,0 ; 10,0$ e 20,0\%). Zanoni (1996), trabalhando com pacu, não observou diferença significativa dos teores de proteína bruta, cinzas, extrato etéreo e matéria seca. Em estudo com a piracanjuba, Garcia et al. (1999) observou aumento dos teores de proteína bruta e diminuição dos de extrato etéreo e matéria mineral.

A inclusão de óleo nas rações não afetou a porcentagem de matéria seca (MS) da carcaça, assemelhando-se aos resultados obtidos por Hanley
(1991) e diferindo dos obtidos por Van der Meer et al. (1997), que observaram aumento proporcional aos níveis de lipídios. Entretanto, proporcionou peixes com menores $(\mathrm{P}<0,01)$ teores de proteína bruta $(\mathrm{PB})$ e maiores $(\mathrm{P}<0,01)$ teores de EE da carcaça (Tabela 6), diferindo dos resultados obtidos por Hanley (1991), que observou que níveis crescentes de lipídios não afetaram a porcentagem de proteína bruta da carcaça, porém afetaram a porcentagem de gordura.

Macroscopicamente não foram observadas alterações morfológicas no sistema digestório dos peixes

R. Bras. Zootec., v.33, n.6, p.2177-2185, 2004 (Supl. 3) 
Tabela 6 - Médias das variáveis rendimento de carcaça (RC), gordura visceral (GV), índice hepatossomático (IHS), matéria seca (MS), proteína bruta (PB) e extrato etéreo (EE) da carcaça em função de óleo

Table 6 - Means for variance for carcass yield (CY), visceral fat (VF), hepatosomatic índex (HSI), dry mater (DM), crude protein $(C P)$ and ether extract (EE) of the carcass as a function of the oil

\begin{tabular}{|c|c|c|c|c|c|c|}
\hline \multirow[b]{2}{*}{$\begin{array}{l}\text { Nível de óleo } \\
\text { Oil level }\end{array}$} & \multicolumn{6}{|c|}{$\begin{array}{l}\text { Variável } \\
\text { Variable }\end{array}$} \\
\hline & $\begin{array}{c}\mathrm{RC}(\%) \\
C Y\end{array}$ & $\begin{array}{c}\mathrm{GV}(\mathrm{g}) \\
V F\end{array}$ & $\begin{array}{c}\text { IHS (\%) } \\
H S I\end{array}$ & $\begin{array}{c}\mathrm{MS}(\%) \\
D M\end{array}$ & $\begin{array}{c}\mathrm{PB}(\%) \\
C P\end{array}$ & $\begin{array}{c}\mathrm{EE}(\%) \\
E E\end{array}$ \\
\hline $\begin{array}{l}0 \% \\
10 \%\end{array}$ & $\begin{array}{l}61,03 a \\
58,29 a\end{array}$ & $\begin{array}{l}0,069 \mathrm{~b} \\
0,257 \mathrm{a}\end{array}$ & $\begin{array}{l}1,11 \mathrm{a} \\
1,17 \mathrm{a}\end{array}$ & $\begin{array}{l}87,98 \mathrm{a} \\
88,06 \mathrm{a}\end{array}$ & $\begin{array}{l}81,72 \mathrm{a} \\
77,20 \mathrm{~b}\end{array}$ & $\begin{array}{r}4,75 b \\
12,56 \mathrm{a}\end{array}$ \\
\hline
\end{tabular}

a,b Médias, na coluna, seguidas de letras diferentes, diferem $(P<0,01)$ pelo teste $F$.

$a, b$ Means, in column, followed by different letters, differ $(P<.01)$ by $F$ test.

dos diferentes tratamentos. Entretanto, observou-se fígado gorduroso, destacadamente nos peixes dos tratamentos com $9 \%$ de fibra com ou sem suplementação de óleo, além de maior deposição de gordura visceral. Não foram observadas alterações microscópicas no epitélio intestinal das tilápias dos diferentes tratamentos. Não se detectaram alteração na mucosa intestinal, aumento no número de células caliciformes e absortivas, ou alteração no comprimento das pregas intestinais. Estes resultados assemelham-se aos obtidos por Oliveira (1994), em estudo com a tilápia do Nilo, com peso inicial médio de $1,52 \pm 0,04 \mathrm{~g}$, alimentada com rações contendo $10,0 \%$ de fibra bruta. Entretanto, diferem dos obtidos por Garcia et al. (1999), que observaram que os peixes dos tratamentos com níveis maiores de fibra bruta apresentaram comprimento de pregas intestinais e número de células caliciformes maiores.

A inclusão de fibra bruta nas rações melhorou a composição da carcaça embora haja tendência de maior deposição de extrato etéreo com a elevação dos níveis de fibra bruta na ração. Embora o melhor ganho de peso foi obtido com a inclusão dos níveis mais baixos de fibra bruta nas rações, este pode ter sido em função do maior teor de gordura visceral e deposição de lipídios no fígado, ocasionado, provavelmente, pelo maior nível energético desta ração (Tabelas 1 e 5).

Por outro lado, os peixes alimentados com as rações suplementadas com $10,00 \%$ de óleo pioraram a composição de carcaça, resultando em menores níveis de proteína e maiores de gordura, o que pode acarretar problemas para seu armazenamento e comercialização, além de elevarem significativamente o teor de gordura visceral.

\section{Conclusões}

Pode-se utilizar na dieta da tilápia do Nilo, na fase de alevinagem $(6,4$ a 31,0g), até $9,00 \%$ de fibra bruta.

A suplementação de níveis excessivos de lipídeos na dieta para alevinos de tilápia do Nilo piora a composição da carcaça e resulta em maior depósito de gordura visceral.

\section{Literatura Citada}

ANDERSON, J.; JACKSON, A.J.; MATTY, A.J. et al. Effects of dietary carbohydrate and fibre on the tilapia (Orechromis niloticus). Aquaculture, v.37, p.303-314, 1984.

AUSTRENG, G. Digestibility determination in fish using chromic oxide making and analysis of contents from different segments of the gastrointestinal tract. Aquaculture, v.13, p.265-75, 1978.

BUHLER, D.R.; HALVER, J.E. Nutrition of salmoid fishes. IX. Carboidrate requeriments of Chinook salmon. Journal of Nutrition, v.74, p.305-318, 1961

CANTELMO, O.A. Nutrição de peixe e aqüicultura. In: HERNANDEZ, A. (Ed.) Cultivo de colossoma. Bogotá: Guadalupe, 1989. p.85-91.

CAStagnolli, N.; CYRINO, J.E.P. Piscicultura nos trópicos. 1.ed. São Paulo: Manuel, 1986. 143p.

DIOUNDICK, O.B.; STOM, D. Effects of dietary á-cellulose on the juvenile tilapia, Oreochromis mossambicus (Peters). Aquaculture, v.91, n.3/4, p.311-315, 1990.

DUPREE, H.K.; SNEED, K.E. Response of channel catfish fingerlings to different levels of major nutrients in purified diets. Bureau of Sport Fisheres and Wildlife. U. Technical Paper n.9, 1966.

EL-SAYED, A.F.M. Evaluation of sugarcane bagasse as a feed ingredient for the tilapias, Oreochromis niloticus and tilapia Zilli. Asian Fisheries Science, v.4, p.53-60, 1991.

GARCIA, R.E.; PEZZATO, L.E.; FILHO, E.Z. et al. Utilização da fibra bruta na nutrição de piracanjuba (Brycon orbignyanus). Acta Scientiarum, v.21, n.3, p.725-731, 1999.

HANLEY, F. Effects of feeding suplementary diets containing varying levels of lipid on growth, food conversation, and 
body composition of Nile tilapia, Oreochromis niloticus. Aquaculture, v.93, p.323-324, 1991.

HEPHER, B. Nutrition of pond fishers. New York: Cambridge University Press, 1988. 386p.

HILTON, J.W.; ATKINSON, J.L.; SLINGER, S.J. Effect of increased dietary fiber on the growth of raimbow trout (Salmo gairdinerri). Canadian Journal of Fisheries and Aquatic Sciences, v.40 p.81-85, 1983.

JAUNCEY, K., ROSS, B. A guide to tilapia feed and feeding. University of Stirling, Scotland: Institute of Aquaculture, 1982. 101p.

LEARY, D.F., LOVELL, R.T. Value of fiber in production-type diets for cannel catfish. Transactions of the American Fisheries Society, v.2, p.328-332, 1975.

NATIONAL RESEARCH COUNCIL - NRC. Nutrient requirements of fish. Washington, D.C.: National Academy of Sciences, 1993. 102p.

NOSE, T. Recent advances in the study of fish digestion in Japan. In: SIMPOSIUM ON FINFISH NUTRITION AND FISH FEED TECHNOlOGY, 1966, Belgrade. Proceedings... EIFAC/FAO, 1966, p.15 sc II-7.

OLIVEIRA, A.C.B. Efeito da inclusão de dendê (Eleaeis guineensis) no desempenho produtivo da tilápia do nilo (Oreochromis niloticus).Botucatu: Universidade Estadual Paulista, 1994. 43p. Dissertação (Mestrado em Zootecnia) Universidade Estadual Paulista, 1994.

PEREIRA-FILHO, M.; CASTAGNOLLI, N.; STORTI-FILHO, A. et al. Efeito de diferentes níveis de proteína e de fibra bruta na alimentação de juvenis de matrinxã (Brycon cephalus). Acta Amazonica, v.24, n.3-4, p.1-8, 1994.
PEZZATO, L.E. Alimentos mais utilizados para peixes. In: CASTAGnOLli, N. (Ed.) Piscicultura. Jaboticabal: FUNEP, 1990. p.87-99.

SHIAU, S.Y.; YU, H.L.; HWA, S. et al. The influence of carboxymethycellulose on growth, digestion, gastric emptying time and body composition of tilapia. Aquaculture, v.70, p.345-354, 1988.

Van der MEER, M.B.; ZAMORA, J.E.; VERDEGEM, M.C.J. Effect of dietary lipid level on protein utilization and the size and proximate composition of body compartments of Colossoma macropomum. Aquaculture Research, v.28, p.405-417, 1997.

WILLIANS, C.H.; DAVID, D.J.; IISMAA, O. The determination of chromic oxide in feces samples by atomic absorption spectrophotometry. Journal of Agriculture Science, v.59, p.381-385, 1962.

ZANONI, M.A. Níveis de fibra bruta em dietas de crescimento do pacu (Piaractus mesopotamicus) HOLMBERG, 1887. Florianópolis: Universidade Federal de Santa Catarina, 1996. 66p. Dissertação (Mestrado em Aqüicultura). Universidade Federal de Santa Catarina, 1996.

Recebido em: 23/02/03

Aceito em: 10/09/04 